\title{
Splenic Infarction in Plasmodium Falciparum Malaria: Case Report and Review of Literature
}

\author{
Dwivedi $D^{1}$, Singh J²
}

\begin{abstract}
Splenic involvement is frequently observed during malarial episode. This involvement may vary from simple asymptomatic splenic enlargement to serious complication such as hematoma, rupture, or infarction. Very few cases of splenic infarction in paediatric patients are reported in literature. This case report suggests that if a patient with malaria is complaining of left upper quadrant abdominal pain, and/or enlarging tender splenomegaly is observed during treatment, splenic infarct should be suspected and managed accordingly to avoid further life-threatening complications.
\end{abstract}

Key words: Malaria, vivax, falciparum, splenic infarction, splenic rupture, MRI abdomen

\section{Introduction}

$\mathrm{M}$ alaria is still the most important parasitic disease known to humans. Splenic involvement is frequently observed during malarial episode. This involvement may vary from simple asymptomatic splenic enlargement to serious complication such as hematoma, rupture, or infarction ${ }^{1,2}$. Very few cases of splenic infarction in paediatric patients are reported in literature ${ }^{3,4}$. We report a case of splenic infarction in falciparum malaria diagnosed by MRI abdomen.

\section{The Case}

A 14 year old female child was admitted with complaints of fever and pain in abdomen. On examination, patient had pallor, tender splenomegaly $5 \mathrm{~cm}$ below costal margin, hepatomegaly $3 \mathrm{~cm}$ below costal margin and severe anaemia $(\mathrm{Hb} 3 \mathrm{gm} / \mathrm{dl})$. Peripheral smear showed trophozoites of falciparum malaria and rapid diagnostic test was also positive. A diagnosis of splenic abscess was made on the basis of perisplenic collection demonstrated on ultrasonography, for which intravenous antibiotic (Inj Amoxycillin-clavlunic acid $90 \mathrm{mg} / \mathrm{kg} / \mathrm{d}$ thrice a day, inj amikacin $15 \mathrm{mg} / \mathrm{kg} /$ day once a day and inj metronidazole $30 \mathrm{mg} / \mathrm{kg} /$ day thrice a day) were added with intravenous Artesunate $(2.4 \mathrm{mg} / \mathrm{kg} /$ day once a day). But since the symptoms did not improved, MRI abdomen was performed which showed multifocal peripheral wedge shaped areas of altered signal in spleen suggestive of splenic infarction on T2W Fat suppression
'Dr. Deepak Dwivedi, MBBS, MD. Assistant Professor, ${ }^{2}$ Dr. Jyoti Singh, MBBS, MD. Both from the Department of Paediatrics, Gandhi memorial Hospital, SS Medical College, APS University, Rewa, Madhya Pradesh, India.

Address for correspondence:

Dr. Deepak Dwivedi

E-mail: deepakdwi72@gmail.com

\section{How to cite}

Dwivedi D, Singh J. Splenic Infarction in Plasmodium Falciparum Malaria: Case Report and Review of Literature. J Nepal Paediatr Soc 2015;35(3):298-300.

doi: http://dx.doi.org/10.3126/jnps.v35i3.12448

This work is licensed under a Creative Commons Attribution 3.0 License.

\section{(c) (7)}

image (fig. 1). As patient was not responding to Artesunate, antimalarial was changed to Quinine $(30 \mathrm{mg} / \mathrm{kg} /$ day) which showed dramatic improvement. The patient was discharged after complete recovery.

\section{Discussion}

The occurrence of splenic infarct in P. falciparum is explained by the ability of its mature trophozoite and schizont forms to sequester in the deep venous microvasculature, whereas sequestration is not a feature of P. vivax. What could have possibly led to splenic infarction in these patients is sudden enlargement of the spleen in response to overwhelming infection with subsequent hypoxic injury ${ }^{3}$. Another mechanism for splenic infarct in vivax cases may be from obstruction produced by hyperplasia of the reticularlike cells located within the walls of venous sinuses ${ }^{5}$. 


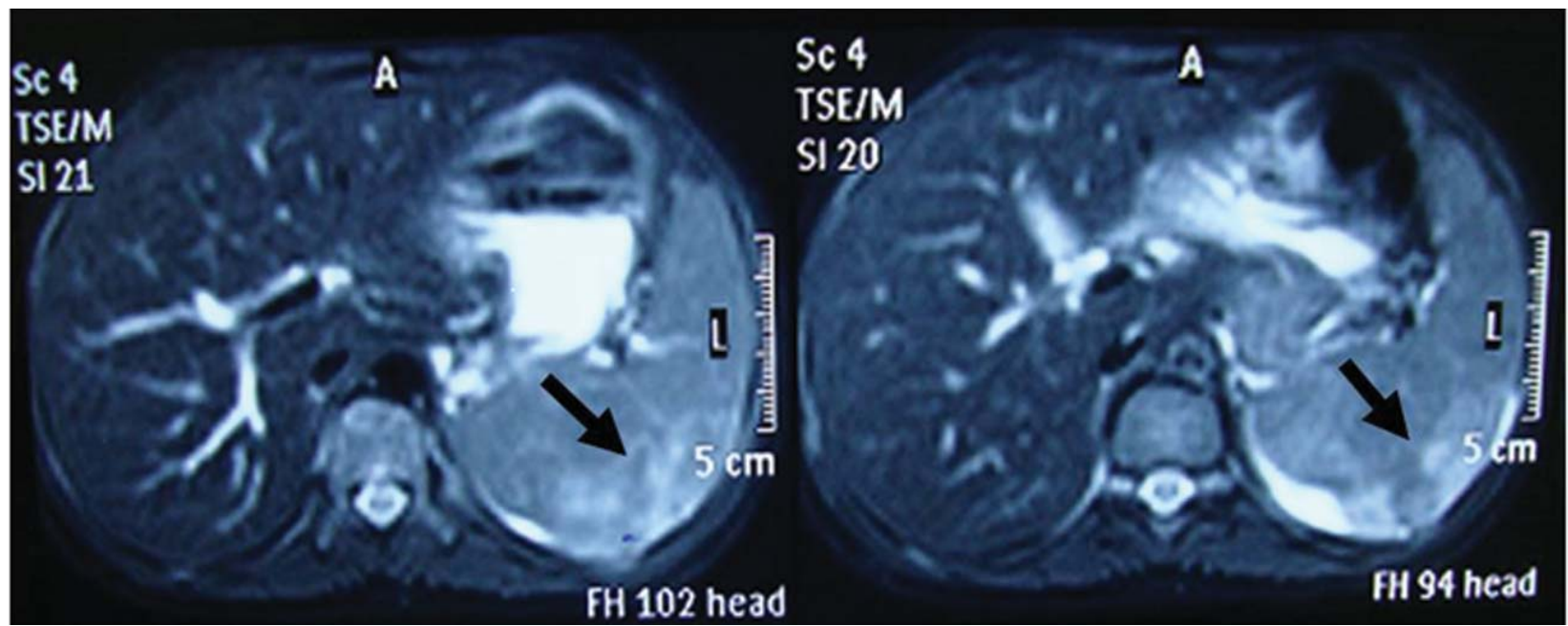

Fig 1: Showing areas of splenic infarction (black arrow) in MRI T2W Fat suppression images.

A Medline search on PubMed (http://www.ncbi. nlm.nih.gov/PubMed/) for 'malaria' AND splenic infarction' revealed in 28 papers. On analysing the papers we found that 10 papers did not mention cases of splenic infarction in there text. Remaining 17 papers were selected for this review of literature ${ }^{3,5-21}$.

The first case was reported in 1975 by French authors Christoforov B et al which were associated with falciparum malaria ${ }^{20}$. On analysing all the papers till date we found that total 24 cases of splenic infarction in malarial patients were reported. Out of these 24 cases 9 were in patients with falciparum ${ }^{3,5,12,14,15,16,17,18,19,20}$ while 11 cases were with P. vivax ${ }^{5,6,7,8,9,11,13}$ and 3 cases had mixed infection ${ }^{5,11}$. One case was of $P$. ovale reported in France in a young officer who had worked in Nigeria ${ }^{10}$. Majority of cases of splenic infarction in malarial patients were reported from India and France. Of these cases till date only 4 cases in paediatric patients have been reported, all of these are from India $6,11,14,15$. Most commonly used diagnostic modality for splenic infarction was Ultrasonography that diagnosed it in 12 cases $^{5,6,8,14,15,17,18,20}$. CT scan abdomen was needed in 8 of these cases $^{3,7,10,11,12,13,16,19}$ Out of which nine cases diagnosed by CT scan one case had normal USG findings. MRI abdomen was done in only one case for confirmation of diagnosis ${ }^{10}$. Only one case had complicated splenic haemorrhage and required surgical treatment ${ }^{12}$, rest all other cases resolved with conservative treatment.

Plasmodium vivax was the most common strain associated with splenic infarction.In our case also we diagnosed splenic infarction with MRI abdomen as diagnosed by other authors ${ }^{10}$ although most of the authors used CT scan and USG for diagnosing the condition. All the cases described in literature had excellent prognosis, except one ${ }^{12}$, with spontaneous recovery in most of the patients with anti-malarial treatment as was there in our case.

\section{Conclusion}

Splenic infarction may be a life threatening complication due to splenic rupture or may be complicated by splenic abscess needing surgical intervention. So prompt evaluation of left subcoastal tenderness in malarial patients should be done. Evaluation should also include CT or MRI abdomen even if Ultrasound is normal, otherwise it is possible that many cases of splenic infarction in malaria may be missed or may remain undiagnosed.

\section{References}

1. Ozsoy MF, Oncul O, Pekkafali Z et al. Splenic complications in malaria: report of two cases from Turkey. J Med Microbiol 2004; 53:1255-58.

2. Hamel CT, Blum J, Harder F, Kocher T. Nonoperative treatment of splenic rupturein malaria tropica: review of the literature and case report. Acta Trop 2002;82:1-5.

3. Bonnard P, Guiard-Schmid JB, Develoux M et al. Splenic infarction during acute malaria. Trans $R$ Soc Trop Med Hyg 2005; 99:82-6.

4. Zingman BS, Viner BL. Splenic complications in malaria; case report and review. Clin Infect Dis 1993; 16:223-32.

5. B.K. Gupta, Kapil Sharma, K.C. Nayaka, T.D. Agrawala, et al. A case series of splenic infarction during acute malaria in northwest Rajasthan, India. Trans R Soc Trop Med Hyg 2010; 104(1):81-3. 
6. Tamaria KC, Agarwal S Splenic infarction in P.vivax malaria. Indian Pediatr 2013; 50(9):886.

7. Thabah MM, Kumar M, Ramesh A, et al. A case of vivax malaria with splenic infarction. J Vector Borne Dis 2013;50(1):74-6

8. Aggarwal HK, Jain D, Kaverappa V et al. Multiple splenic infarcts in acute Plasmodium vivax malaria: a rare case report. Asian Pac J Trop Med 2013;13;6(5):416-18

9. Sonkar SK, Uniyal R, Sonkar GK. Three unusual presentations of plasmodium vivax malaria. Trop Doct 2011;41(4):240-41

10. Cinquetti G, Banal F, Rondel C, Plancade D, et al. Splenic infarction during Plasmodium ovale acute malaria: first case reported. Malar J 2010;9:288

11. Kumar BG, Shetty MA, Chakrapani. Splenic complications in malaria: a case series. Southeast Asian J Trop Med Public Health 2008; 39(5):79194.

12. Balfe P, Reynolds JVA rare cause of acute abdomen--plasmodium falciparum leading to splenic infarction and haemorrhage. Ir Med J 2008;101(5):150-51.

13. Kim A, Park YK, Lee JS, Chung MH, Kim ESA case of symptomatic splenic infarction in vivax malaria. Korean J Parasitol 2007;45(1):55-8.
14. Agarwal VK, Agarwal S, Pathak T. Splenic infarct in falciparum malaria. Indian Pediatr 1997;34(11):1050-51.

15. Sur AK, Khawash N, Mitra PK, et al. Splenic infarct in falciparum malaria. Indian Pediatr 1997;34(1):72

16. Hovette P, Lecoules S, Boete F, et al. Splenic infarction during P. falciparum and P. vivax malaria. Presse Med 1994;23(26):1226.

17. Singh BJ, Kumar A Splenic infarctions in mixed infection with kalaazar and falciparum malaria. $J$ Assoc Physicians India 1991;39(3):293.

18. Salord F, Allaouchiche B, Gaussorgues $P$ et al. Severe falciparum malaria (21 cases). Intensive Care Med 1991;17(8):449-54.

19. Coche G, Estavoyer JM, Leroy J, Costaz R Splenic infarction in Plasmodium falciparum malarial attack. J Radiol 1990;71(8-9):473-75.

20. Christoforov B, Chiche B, Duflo B, et al. Splenic infarction in primary Plasmodium falciparum infection]. Ann Med Interne (Paris). 1976;127(1):479.

21. Imbert P, Buffet P, Ficko C, Rapp C. Left upper quadrant abdominal pain in malaria: suspect pathological splenic rupture first. Trans $R$ Soc Trop Med Hyg 2010;104(9):628. 